\title{
Determinants of Subjective Poor Sleep Quality in Social Media Users Among Freshman College Students
}

Adam F Aldhawyan

Ali A Alfaraj

Sara A Elyahia

Shaher Z Alshehri $\mathbb{D}$

Amal A Alghamdi

Family and Community Medicine Department, College of Medicine, Imam Abdulrahman Bin Faisal University,

Dammam, Saudi Arabia

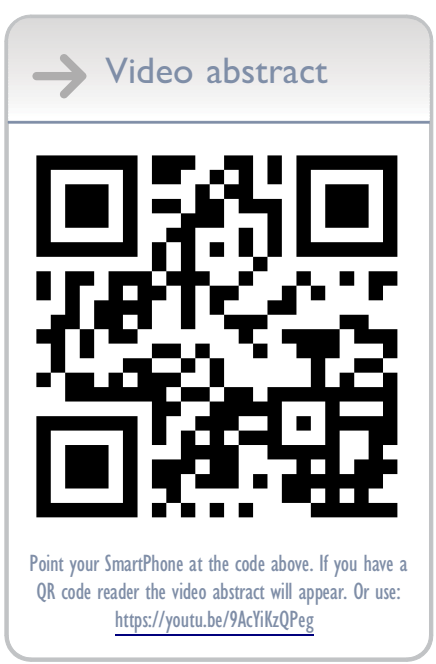

Correspondence: Adam F Aldhawyan Family and Community Medicine Department, College of Medicine, Imam Abdulrahman Bin Faisal University, Dammam 34221 - 4237, Saudi Arabia

Tel +966503838700

Fax +966 I33330220

Email aaaldhawyan@iau.edu.sa
This article was published in the following Dove Press journal: Nature and Science of Sleep

Introduction: Social media (SM) usage has increased markedly among young adults. It is linked to poor sleep quality (PSQ), a risk factor for mental and physical health concerns. This study identified the determinants of PSQ in SM users among freshman college students.

Material and Methods: A cross-sectional design was used and 842 students completed a self-administered questionnaire. Analyses were performed using the $\chi^{2}$ test to examine differences in the characteristics of poor and good sleepers and logistic regression to estimate the risk of PSQ with reference to SM usage patterns.

Results: Around $75.40 \%(n=635)$ of the participants had PSQ. There was a significant difference in the PSQ rate between males $(66.3 \%)$ and females $(79.3 \%, p<0.001)$, those who were physically active $(67.2 \%)$ and those who were not $(82.4 \%, \mathrm{p}<0.001)$, those who were mentally depressed $(86.5 \%)$ and those who were not $(61.5 \%, \mathrm{p}<0.001)$, and those with anxiety $(87.8 \%)$ and those without $(64.3 \%, \mathrm{p}<0.001)$. The risk of PSQ was lower among students who used SM for education ( $\mathrm{OR}=0.65, \mathrm{CI}=0.42$ to $0.99, \mathrm{p}=0.048$ ), had higher laptop usage $(\mathrm{OR}=0.67, \mathrm{CI}=0.47$ to $0.96, \mathrm{p}=0.03)$, and had higher SM usage during daytime $(\mathrm{OR}=0.46, \mathrm{CI}=0.32$ to $0.67, \mathrm{p}<0.001)$. The risk of PSQ was higher among those who reported SM usage at bedtime $(\mathrm{OR}=1.69, \mathrm{CI}=1.01$ to $2.81, \mathrm{p}=0.046)$.

Discussion: Among SM users, PSQ was related to sociodemographic features, lifestyle characteristics, and health-risk factors. Further research is required to confirm these findings. Keywords: PSQI, sleep hygiene, social network, medical students, young adults, Saudi Arabia

\section{Introduction}

Sleep is a condition in which the body temporarily and partially loses its connection with the environment. ${ }^{1}$ Sleep has been assessed using either subjective or objective tools. Overnight Polysomnography (PSG) is the only objective measure of sleep parameters. Questionnaires are one of the widely used subjective tools utilized to assess sleep quality by measuring different sleep indicators such as prolonged sleep latency, sleep duration, sleep efficacy, and sleep disturbance. Adolescents' and young adults' sleep patterns and sleep quality can be affected by several biological, psychosocial, and environmental factors. ${ }^{2}$ Today, poor sleep quality (PSQ) is a very common problem among young adults. A study of 11,557 high school students in Brazil showed that the prevalence of PSQ increased from 31\% to $46 \%$ between 2001 and 2011. ${ }^{3}$ Similarly, two studies conducted in Turkey and Sudan revealed that $79.62 \%$ and $61.4 \%$ of medical students experienced PSQ, respectively. ${ }^{1,4}$ In 
2019 , a study on medical students from two colleges in the western region of Saudi Arabia revealed that $67.1 \%$ of the participants experienced PSQ. ${ }^{5}$ PSQ and insufficient hours of sleep are associated with a wide range of poor health outcomes, including obesity, ${ }^{6}$ diabetes mellitus, ${ }^{1}$ high blood pressure, ${ }^{1}$ cardiovascular disorders, ${ }^{7}$ anxiety, ${ }^{8}$ depression, and poor mental health. ${ }^{9,10}$ Additionally, disturbed sleep is linked to substance abuse, ${ }^{11}$ poor judgment, ${ }^{12}$ and an increase in low academic performance among adolescents. ${ }^{13,14}$ Recently, poor sleep has been linked with excessive usage of $\mathrm{SM},{ }^{15}$ which is defined as

the wide range of Internet-based and mobile services that allow users to participate in online exchanges, contribute user-created content, or join online communities. ${ }^{16}$

The social media usage rate has increased dramatically over the last few years. ${ }^{2}$ However, as reported by two recent studies conducted in Canada and the United Kingdom, the longer the period of SM usage, the shorter is the sleep duration and the worse is the sleep quality. ${ }^{15,17}$ Although sleep research has increased recently, only a few studies conducted in the Middle East have specifically examined the effects of SM usage on young adults, who exhibit a high rate of SM use and insufficient sleep.

\section{Aim}

This study aimed to investigate the rate of PSQ among freshman college students and to identify the determinants of PSQ, including their sociodemographic features, lifestyle characteristics, and health-risk factors. Additionally, it aimed to describe the pattern of SM usage among this sample and to explain its relationship with poor quality of sleep. Thus, it was hypothesized that different patterns of social media usage affect the sleep quality of freshman college students.

\section{Materials and Methods}

This cross-sectional study was conducted in the academic year of 2018-2019 at College of Medicine, Imam Abdulrahman bin Faisal University (IAU), Dammam, Eastern Province of Saudi Arabia. Before the commencement of the study, ethical approval was obtained from the Institutional Review Board of IAU. Using a selfadministered questionnaire, this study targeted freshman students who were in their first academic year (this year is considered as a foundation year for health and medical studies). Participants provided written informed consent after we explained that they have the right to refuse to participate or withdraw from the study at any point; that their information will be kept confidential and will only be used for research purposes; and that their participation/ refusal would not affect their academic evaluation. The participants included all male and female students who consented to participate. The questionnaire sought data about participants' sociodemographic features, lifestyle risk factors, and health status (Tables 1 and 2). Patterns of SM usage were assessed using five questions that evaluated the following aspects: types of SM platforms used, purpose of SM usage, types of devices used for SM activity, length of SM usage during bedtime and daytime, and frequency of SM usage per day and per week (for further information please refer to the supplemental material Table S1). The validated Arabic version of the Pittsburgh Sleep Quality Index (PSQI) was used. ${ }^{18}$ The PSQI comprises 19 items across seven sleep components that subjectively quantify respondents' sleep quality over the past month. The sum of scores on items provides the global PSQI score, which ranges from 0 to 21 , with a score equal to or more than 5 indicating PSQ. Depression and anxiety were measured using global scores on two validated screening tools; the two-item Patient Health Questionnaire (PHQ-2) ${ }^{19}$ was used to assess the frequency of depression experienced and the two-item Generalized Anxiety Disorder (GAD-2) ${ }^{20}$ was used to screen for the presence of anxiety disorder (for further information please refer to the supplemental material Table S2). SPSS (version 21) was used for the data analysis. In addition to bar graphs, a cross-tabulation of counts and percentages was used to describe the distribution of the categorical variables, while the mean, standard deviation, and range were used to describe the distribution of the continuous variables. A chi-square test was used to examine the differences in the proportions of sociodemographic features, lifestyle characteristics, and health-risk factors between participants with poor and good sleep quality. Unadjusted and adjusted regression logistic models were used to examine the risk of PSQ in relation to patterns of SM usage. In the regression models, adjustment variables were chosen after investigating the literature and drawing a hypothetical-directed acyclic graph ${ }^{21}$ which is a visual representation of the relationship between study variables. Each variable is represented with a node, while the directions of the relationships between the included variables are represented by unidirectional arrows. The direction of the arrows and location of variables within the graph indicate the role of the variables within the study (ie, 
Table I The Distribution of Sociodemographic Features and Their Differences Among Participants with Poor and Good Sleep Quality, as Measured by PSQI Score

\begin{tabular}{|c|c|c|c|c|c|c|c|}
\hline & & \multicolumn{3}{|l|}{ Sleep Quality } & \multirow{2}{*}{$\begin{array}{l}\text { Chi- } \\
\text { Square }\end{array}$} & \multirow[t]{2}{*}{ DF } & \multirow[t]{2}{*}{ p-value } \\
\hline & & Good $n=207(24.6 \%)$ & Poor $n=635(75.4 \%)$ & Total $n=842$ & & & \\
\hline Gender & $\begin{array}{l}\text { Male } \\
\text { Female }\end{array}$ & $\begin{array}{l}85(33.70) \\
122(20.70)\end{array}$ & $\begin{array}{l}167(66.30) \\
468(79.30)\end{array}$ & $\begin{array}{l}252 \\
590\end{array}$ & 15.635 & I & $<0.001$ \\
\hline Social status & $\begin{array}{l}\text { Married } \\
\text { Unmarried }\end{array}$ & $\begin{array}{l}10(24.40) \\
179(24.60)\end{array}$ & $\begin{array}{l}31(75.60) \\
604(75.40)\end{array}$ & $\begin{array}{l}41 \\
801\end{array}$ & 1.698 & 2 & 0.428 \\
\hline Economic status & $\begin{array}{l}\text { Higher social class } \\
\text { Lower social class }\end{array}$ & $\begin{array}{l}164(25.50) \\
43(21.50)\end{array}$ & $\begin{array}{l}478(74.80) \\
157(78.50)\end{array}$ & $\begin{array}{l}642 \\
200\end{array}$ & 1.374 & 1 & 0.143 \\
\hline Employment & $\begin{array}{l}\text { Yes } \\
\text { No }\end{array}$ & $\begin{array}{l}10(41.70) \\
197(24.10)\end{array}$ & $\begin{array}{l}14(58.30) \\
621(75.90)\end{array}$ & $\begin{array}{l}24 \\
818\end{array}$ & 3.742 & 1 & 0.047 \\
\hline Living status & $\begin{array}{l}\text { Alone } \\
\text { With } \\
\text { roommate(s) }\end{array}$ & $\begin{array}{l}155(23.60) \\
52(28.30)\end{array}$ & $\begin{array}{l}503(76.40) \\
132(71.70)\end{array}$ & $\begin{array}{l}658 \\
184\end{array}$ & 1.679 & I & 0.113 \\
\hline $\begin{array}{l}\text { Room } \\
\text { environment }\end{array}$ & $\begin{array}{l}\text { Comfortable } \\
\text { Uncomfortable }\end{array}$ & $\begin{array}{l}185(2.10) \\
22(13.80)\end{array}$ & $\begin{array}{l}497(72.90) \\
138(86.20)\end{array}$ & $\begin{array}{l}682 \\
160\end{array}$ & 13.806 & 1 & $<0.001$ \\
\hline
\end{tabular}

Table 2 Differences Between Health and Behavior Indicators Among Participants with Good and Poor Sleep Quality, as Measured by PSQI Score

\begin{tabular}{|c|c|c|c|c|c|c|c|}
\hline & & \multicolumn{2}{|l|}{ Sleep Quality } & \multirow[b]{2}{*}{ Total $n=842$} & \multirow[t]{2}{*}{ Chi-Square } & \multirow[t]{2}{*}{ DF } & \multirow[t]{2}{*}{ P-value } \\
\hline & & Good $n=207(24.6 \%)$ & Poor $n=635(75.4 \%)$ & & & & \\
\hline Smoking & $\begin{array}{l}\text { Yes } \\
\text { No }\end{array}$ & $\begin{array}{l}15(24.20) \\
192(24.60)\end{array}$ & $\begin{array}{l}47(75.80) \\
588(75.40)\end{array}$ & $\begin{array}{l}62 \\
780\end{array}$ & 0.006 & I & 0.540 \\
\hline Alcohol & $\begin{array}{l}\text { Yes } \\
\text { No }\end{array}$ & $\begin{array}{l}4(36.40) \\
203(24.40)\end{array}$ & $\begin{array}{l}7(63.60) \\
628(75.60)\end{array}$ & $\begin{array}{l}11 \\
831\end{array}$ & 0.765 & I & 0.274 \\
\hline Illegal substances & $\begin{array}{l}\text { Yes } \\
\text { No }\end{array}$ & $\begin{array}{l}2(40.00) \\
205(24.50)\end{array}$ & $\begin{array}{l}3(60.00) \\
632(75.50)\end{array}$ & $\begin{array}{l}5 \\
837\end{array}$ & 0.579 & 1 & 0.358 \\
\hline Physical activity & $\begin{array}{l}\text { Yes } \\
\text { No }\end{array}$ & $\begin{array}{l}127(32.80) \\
80(17.60)\end{array}$ & $\begin{array}{l}260(67.20) \\
375(82.40)\end{array}$ & $\begin{array}{l}387 \\
455\end{array}$ & 26.210 & I & $<0.001$ \\
\hline Caffeinated drinks & $\begin{array}{l}\text { Yes } \\
\text { No }\end{array}$ & $\begin{array}{l}158(23.10) \\
49(31.00)\end{array}$ & $\begin{array}{l}526(76.90) \\
109(69.00)\end{array}$ & $\begin{array}{l}684 \\
158\end{array}$ & 4.167 & I & 0.025 \\
\hline Depression & $\begin{array}{l}\text { Score } \geq 3 \\
\text { Score }<3\end{array}$ & $\begin{array}{l}63(13.50) \\
144(38.50)\end{array}$ & $\begin{array}{l}405(86.50) \\
230(61.50)\end{array}$ & $\begin{array}{l}468 \\
374\end{array}$ & 70.901 & 1 & $<0.001$ \\
\hline Anxiety & $\begin{array}{l}\text { Score } \geq 3 \\
\text { Score }<3\end{array}$ & $\begin{array}{l}49(12.20) \\
158(35.70)\end{array}$ & $\begin{array}{l}351(87.80) \\
284(64.30)\end{array}$ & $\begin{array}{l}400 \\
442\end{array}$ & 65.382 & 1 & $<0.001$ \\
\hline Chronic disease & $\begin{array}{l}\text { Yes } \\
\text { No }\end{array}$ & $\begin{array}{l}50(17.60) \\
157(28.10)\end{array}$ & $\begin{array}{l}234(82.40) \\
40 I(71.90)\end{array}$ & $\begin{array}{l}284 \\
558\end{array}$ & 11.713 & 1 & 0.001 \\
\hline BMI & $\begin{array}{l}\text { Underweight } \\
\text { Normal weight } \\
\text { Overweight } \\
\text { Obese }\end{array}$ & $\begin{array}{l}31(23.80) \\
140(27.70) \\
22(16.80) \\
14(18.70)\end{array}$ & $\begin{array}{l}99(76.20) \\
366(72.30) \\
109(83.20) \\
61(81.30)\end{array}$ & $\begin{array}{l}130 \\
506 \\
131 \\
75\end{array}$ & 8.734 & 2 & 0.040 \\
\hline
\end{tabular}


mediator, exposure, or confounder). The choice of the arrow direction and included variables is based on previous literature. For all analyses, the statistical significance level was set at $\mathrm{p}<0.05$.

\section{Results}

In total, 1016 potential participants were approached. However, only $842(82.87 \%)$ had complete data; all participants with missing data were excluded by using listwise deletion. The distribution of the sociodemographic features has been summarized in Table 1. The mean age of the participants was 18.42 years $(\mathrm{SD}=0.68$ years, $\max =$ 24 years, $\min =17$ years). Out of the 842 participants, $75.4 \%(n=635)$ had PSQ. The mean total sleep hours per day were 6.61 (SD $=1.853$ ) hours. Regarding prolonged sleep latency, $68.1 \%$ of the participants $(n=573)$ reported that they could not fall asleep within 30 mins. Concerning sleep disturbance, 57.6\% $(n=485)$ of the participants reported that they woke up in the middle of the night or early morning, $46.3 \%(n=390)$ got out of bed to use the bathroom, $38.4 \%(n=323)$ could not breathe comfortably while sleeping, 19.7\% $(\mathrm{n}=166)$ coughed or snored loudly, 57.2\% $(\mathrm{n}=482)$ felt too cold, $56.5 \%(\mathrm{n}=$ 476) felt too hot, $58.2 \%(\mathrm{n}=490)$ experienced bad dreams, and 47.6\% $(n=401)$ experienced pain. The distribution of scores on sleep quality components has been presented in Figure 1. Table 2 presents the distribution of health indicators and behaviors that are considered to be risk factors for poor health in relation to sleep quality, as identified using the global score on the PSQI. In regard to chronic diseases, $33.7 \%(n=284)$ of the participants were known to have a chronic disease that might contribute to PSQ, 82.4\% $(\mathrm{n}=234)$ of them considered to have PSQ according to their PSQI global score. Among 284 students who had a chronic disease, $68(23.9 \%)$ were diagnosed with bronchial asthma, and $86.8 \%(n=59)$ of them experienced poor quality of sleep as compared to $74.4 \%$ $(\mathrm{n}=576)$ non-asthmatic students. Additionally, $84(29.6 \%)$ out of 284 students were known to have major depression disorder and 198 (69.7\%) were known to have generalized anxiety disorder, which was diagnosed in the hospital. Further, 91.7\% $(\mathrm{n}=77)$ and $84.8 \%(\mathrm{n}=168)$ of them

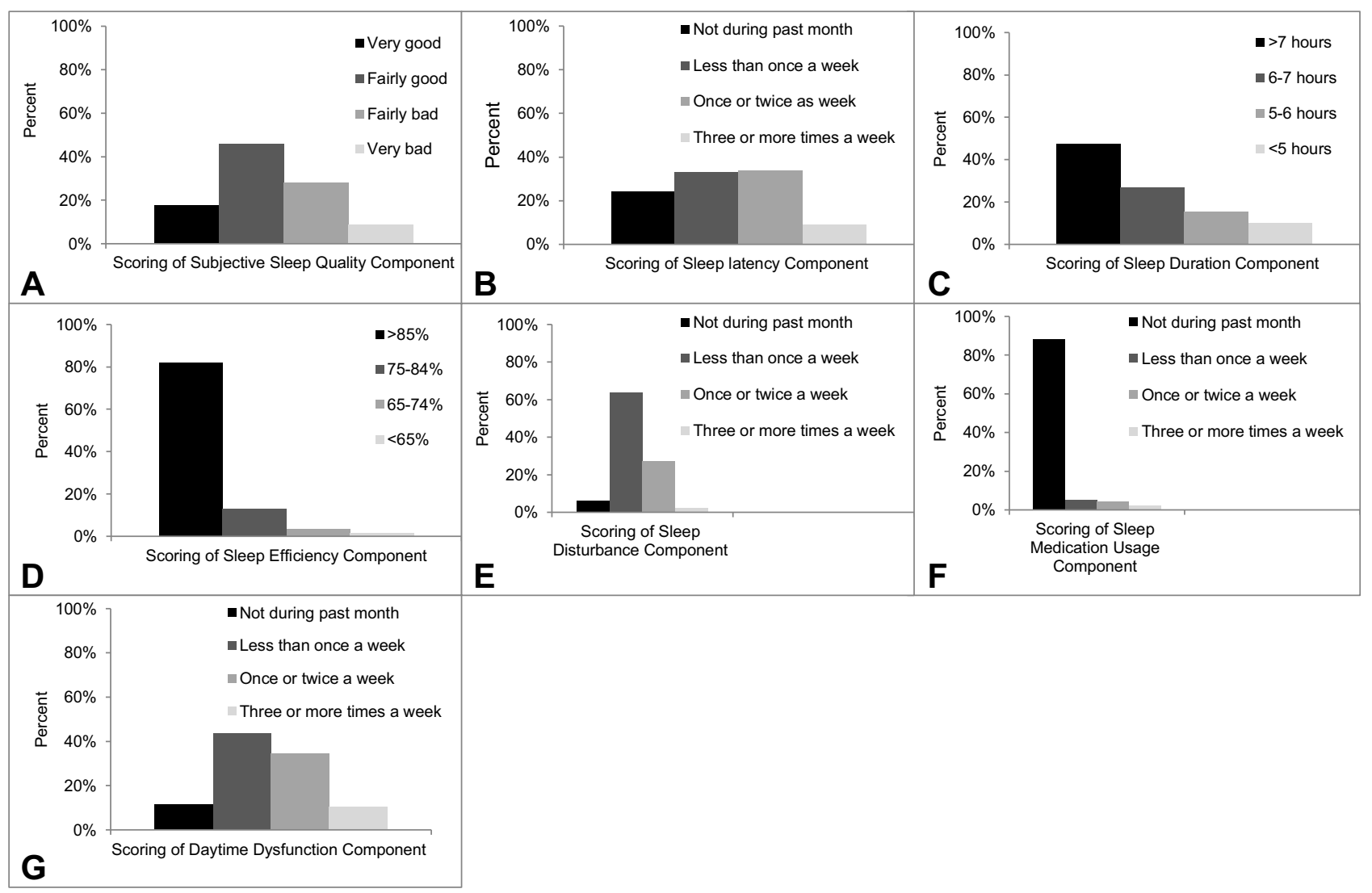

Figure I Bar graphs that show the distribution of the following (A) scoring of subjective sleep quality component, (B) scoring of sleep latency component, (C) scoring of sleep duration component, (D) scoring of sleep efficiency component, (E) scoring of sleep disturbance component, (F) scoring of medication usage component, (G) scoring of daytime dysfunction component. 
reported poor quality of sleep, respectively. Among those who had a chronic disease $(n=284), 38.0 \%(n=108)$ had more than one disease, or they had other co-morbidities like sleep apnea $(n=35,12.3 \%)$, diabetes mellitus $(n=13$, $4.6 \%)$, gastroesophageal reflux disease $(n=14,4.9 \%)$, and heart disease $(n=9,3.2 \%)$. The screening tools utilized in the present study revealed that more than half of the participants may have had depression $(n=468,55.6 \%)$ and $47.5 \%(n=400)$ of them may have had anxiety. As shown in Table 3, majority of the participants used the WhatsApp platform $(\mathrm{n}=813,96.6 \%)$. The most and least common purpose of SM use was entertainment $(\mathrm{n}=779$, $92.5 \%)$ and commercial purposes $(\mathrm{n}=101,12.0 \%)$, respectively. On the other hand, $81.1 \%(n=683)$ of the participants used SM for education and 57.4\% $(\mathrm{n}=392$, $\mathrm{p}<0.001)$ of them browsed SM through their laptops during educational use. Around 90.4\% $(\mathrm{n}=761)$ used $\mathrm{SM}$ at bedtime. However, only 13.7\% ( $\mathrm{n}=104, \mathrm{p}<$ 0.001) of them used SM for longer than $2 \mathrm{hrs}$ before bedtime. On the other hand, majority $(69.5 \%)$ of the participants used SM for longer than 2 hrs per day $(n=585)$ but only $16.10 \%$ of them $(n=94, p<0.001)$ used SM for longer than $2 \mathrm{hrs}$ at bedtime. Additionally, 89.9\% (n = 757) of the participants reported daily usage of SM and $67.9 \%(\mathrm{n}=514, \mathrm{p}<0.001)$ of them used SM more than four times each day. Regarding the relationship between SM and PSQ, the risk of PSQ among SM users was significantly lower among laptop users (unadjusted OR = 0.699 , $\mathrm{CI}=0.445$ to $0.951, \mathrm{p}=0.026$ ) as well as among those students who used SM before bedtime (unadjusted $\mathrm{OR}=0.457, \mathrm{CI}=0.284$ to $0.736, \mathrm{p}=0.001$ ). This relationship was significant even after the adjustment. However, the risk of having PSQ was higher when the duration of SM usage during bedtime was longer (unadjusted OR = $1.685, \mathrm{CI}=1.010$ to $2.813, \mathrm{p}=0.046$ ). On the other hand, the longer the usage of SM during the day, the lower was the risk of PSQ (unadjusted OR $=0.464, \mathrm{CI}=0.335$ to $0.643, \mathrm{p}<0.001$, adjusted $\mathrm{OR}=0.461, \mathrm{CI}=0.318$ to $0.667, \mathrm{p}<0.001)$. Additionally, the risk of PSQ was significantly lower among participants who used SM for educational purposes as compared to those who used SM for other purposes (unadjusted $\mathrm{OR}=0.651, \mathrm{CI}=0.445$ to $0.951, \mathrm{p}=0.026$; adjusted $\mathrm{OR}=0.646, \mathrm{CI}=0.419$ to $0.997, \mathrm{p}=0.048)$.

\section{Discussion}

The main aim of this study was to examine sleep patterns among freshman college students, explore the determinants of PSQ among SM users, describe the pattern of SM usage among students, and investigate the association between PSQ and various aspects of SM usage. This was important because poor sleep patterns are linked to poor physical and mental health, ${ }^{1,22}$ and poor academic performance. $^{13}$ Our study found that over two-thirds of freshman college students experienced PSQ. Although this rate was high, it was similar to that of Portuguese nursing students-reported by Silva et al, ${ }^{23}$ Turkish medical students, ${ }^{1}$ and Saudi medical and dental students. ${ }^{5,13}$ In these previous studies, PSQ among college students was linked to stress resulting from academic life. ${ }^{13,24}$ However, PSQ was, consequently, linked to low GPA achievement and poor academic performance among medical students. ${ }^{13,25}$ PSQ was also reported among Saudi students who were not pursuing medical education. ${ }^{26}$ In the present study, PSQ was mainly related to prolonged sleep latency and disturbance, which might lead to some degree of daytime dysfunction. These, in turn, may be one of the reasons for the effect of PSQ on students' academic performance. Interestingly, in our study, over half of the poor sleepers (as measured by the total PSQI score) subjectively described their sleep quality as good to fairly good, and they reported that they slept for more than 6 hrs at night. This finding indicates the complex nature of sleep and the need for measuring sleep using multiple characteristics rather than focusing on sleep duration alone.

The second aim of our study was to explore the determinants of PSQ among SM users. In our study, females had a higher rate of PSQ as compared to males. This finding was consistent with those reported by prior studies, $2,5,17,26,27$ and it was linked by some authors to fluctuating female hormonal levels that might influence PSQ, especially during menses. ${ }^{28}$ Although our sample did not include many part-time-employed students, findings revealed that those who were employed had poorer sleep quality. The relationship between part-time employment and PSQ might be explained by the stress resulting from balancing academic life and employment duties, or due to the lack of sufficient sleep due to shift times or extended work hours. ${ }^{29}$ Regarding sleep quality and health-risk factors, the present study found that PSQ was common among participants who had a higher BMI, who were inactive, and who had chronic diseases. Furthermore, PSQ was more common among participants with mental health issues (ie, depression and anxiety), as screened using the PHQ-2 ${ }^{19}$ and GAD-2. ${ }^{20}$ However, further 


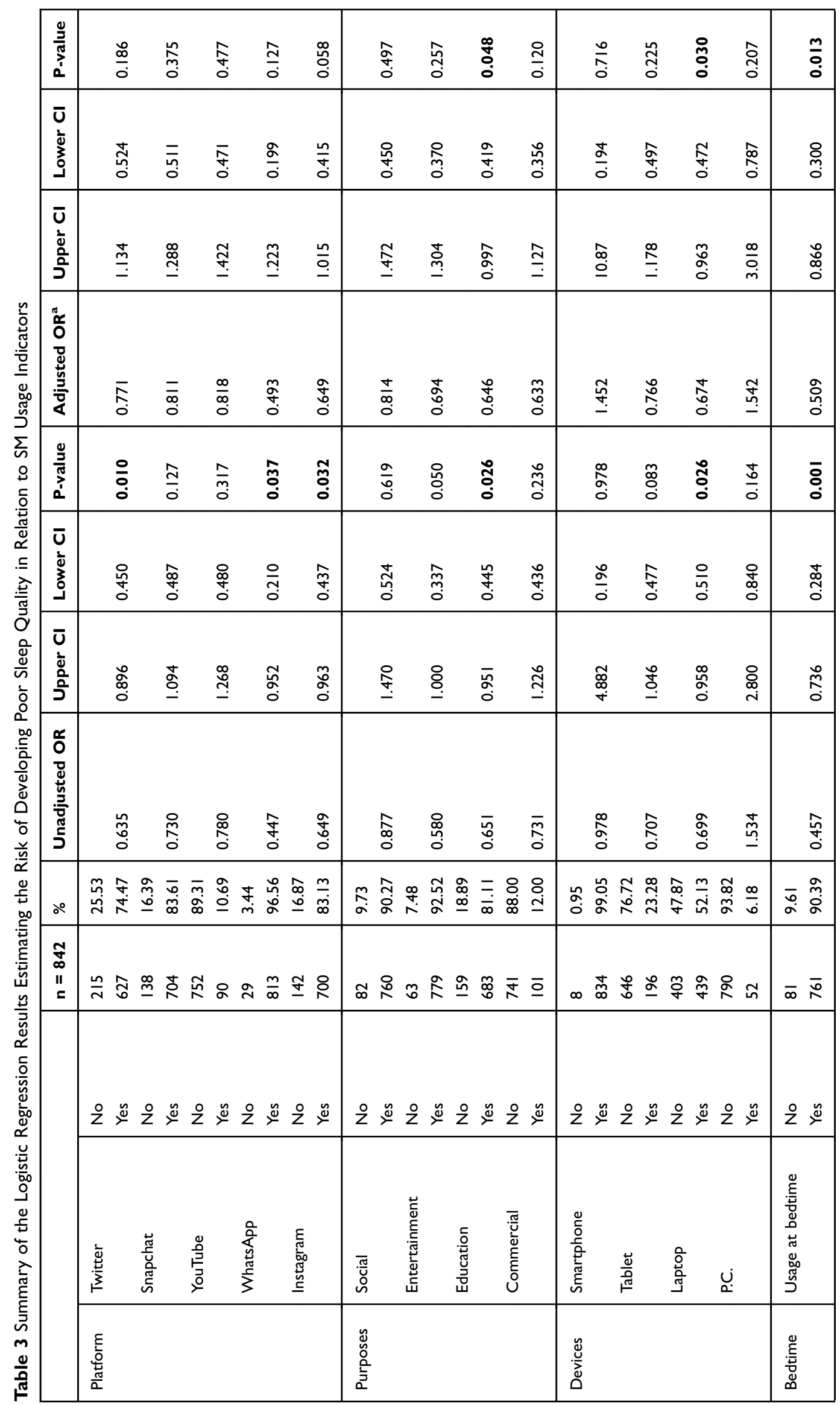




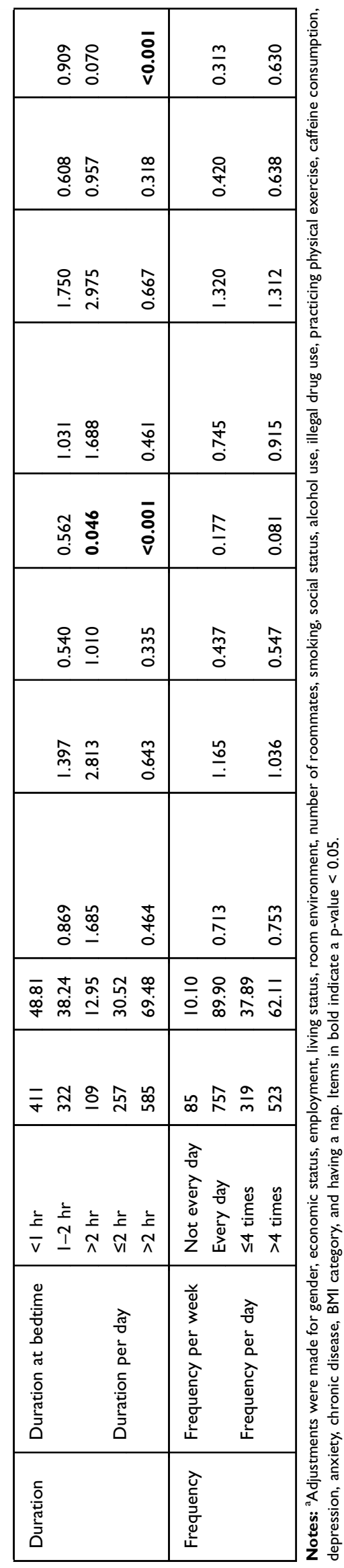

clinical diagnosis would be necessary to confirm the presence of these mental disorders amongst our participants. In fact, sleep disturbance and abnormal sleep duration are considered as characteristics of depression. ${ }^{30}$ Additionally, anxiety is characterized by short sleep duration, sleep fragmentation, and prolonged sleep latency. ${ }^{31}$ Additionally, those who consumed caffeine had a higher rate of PSQ. This could be explained by the brainstimulating nature of caffeine. ${ }^{32}$ Although many students may use caffeine to overcome the physical and cognitive effects of sleep deprivation or to improve concentration in their academic pursuits, ${ }^{33}$ caffeine could have side effects that mask anxiety symptoms and cause low GPA achievement. ${ }^{13,34}$ Additionally, the present study found that caffeine usage ( $>$ two cups) might increase prolonged sleep latency, thus leading to PSQ.

The third aim of this study was to understand the patterns of SM usage among freshman college students. SM use is a broad and complex concept that is challenging to measure (especially in the absence of a measuring tool to classify its users). Additionally, the absence of a cutoff point that differentiates between normal and abnormal levels of SM usage might create a measurement error that might bias the relationship between sleep quality and SM. Unfortunately, researchers have found that students are more prone to SM addiction. ${ }^{35}$ In our study, most of the students reported using SM for more than 2 hrs daily, and they exhibited high scores on the depression and anxiety screening tools. Together, these findings suggest that SM addiction may affect one's self-esteem and life satisfaction. ${ }^{36}$ These factors indicate the need for further SM research to define the parameters delineating normal from abnormal usage (or addiction), and to define the appropriate time for providing interventions for students. In our study, majority of the students browsed SM platforms on their smartphones rather than on other devices. However, excessive smartphone use was linked to eye discomfort, daytime fatigue, and body dysfunction. ${ }^{37}$ Furthermore, smartphone addiction was linked to mental health complications such as depression and anxiety, ${ }^{38}$ which were common among our participants (as assessed using the PHQ- $2^{19}$ and GAD- $2^{20}$ ). The majority of our participants used SM for non-commercial, social, or entertainment purposes. Nonetheless, those who used SM for educational purpose were at a lower risk of developing PSQ. This finding suggests that the purpose of SM usage could play a role in the development of PSQ. However, it is unclear if this relationship existed because of the stress 
from exposure to SM content or due to the prolonged time spent in exploring its contents.

With regard to SM usage indicators as determinants of PSQ, the present findings revealed that the risk of PSQ was low among students who browsed SM using their laptops. Perhaps this finding was correlated with the fact that majority of the participants who used their laptops for browsing SM used them for educational purposes. Additionally, the mobility and small size of smartphones and tablets (as compared to laptops) might tempt their users to carry them to bed and use them for longer durations during bedtime. We found that longer duration of SM usage during the night increased the risk of PSQ, in contrast to longer SM usage during the day. The differences in the risk of PSQ based on length of SM usage during the day and night may be linked with the level of fatigue caused by SM use during the night, as well as the fact that participants who browsed SM for longer durations during the day consequently used it less during the night.

\section{Strengths and Limitations}

Social media and its effect on human well-being are still understudied and not well understood. We studied social media usage comprehensively (by examining the SM platform used, purpose of use, devices used, duration and frequency of SM use, and usage at bedtime) rather than focusing on one area (like Facebook dependency). Our findings might improve the understanding of SM and its impact on sleep and individuals' well-being. We also studied the effects of social-demographic factors that affect sleep quality (gender, economic status, employment, living status, and room environment). Additionally, we studied the relationship of PSQ with lifestyle risk factors and health statuses like chronic disease, body weight, and physical activity. Unfortunately, although our study comprehensively covered many aspects of sleep and complex SM concepts, it was not without limitations. The use of an observational cross-sectional design led to a loss of the temporal sequence of events, which increased the risk of confounding and mediating biases, particularly in the case of the bidirectional relationship between the study variables (such as sleep, depression, SM, and physical activity). Therefore, future studies would benefit from using prospective designs to explore the nature of this bidirectional relationship between variables. Additionally, the observational study design may have increased the risk of unadjusted confounders that we failed to measure. Some of these variables included addiction to smartphones and SM, as we found a high prevalence of anxiety and depression among users, which could be explained by addiction. One of the major limitations of our study was the lack of an accurate objective measurement of sleep using overnight PSG. Unfortunately, this may have caused a measurement error in the assessment of sleep indicators and possible biases in estimated risks. However, the PSQI is an accepted and validated questionnaire, which allowed us to collect sleep data from a large sample as well as to understand the subjective aspects of sleep quality. Unfortunately, the irregularities of menstrual cycles and symptoms of hormonal disturbances amongst female participants were not investigated in our study. Fluctuation in the female sex hormones as well as hormonal changes (especially during menses) might affect sleep quality and duration. ${ }^{28}$ We recommend that future studies consider hormonal factors when examining sleep quality. Additionally, the absence of an SM usage pattern measurement scale, a cutoff point for determining normal and abnormal SM usage, and a guideline to define unhealthy SM usage made it difficult to measure SM accurately. Therefore, SM research might benefit from filling these gaps. Finally, limiting the study sample to one center may affect the generalizability of the present results to other age groups, other university students, or students studying in other academic fields. This may be crucial considering the presence of important confounders that were adjusted for through stratification (such as age, academic specialty, and academic atmosphere). Therefore, further research is required to understand the impact of such confounders on the relationship between sleep and SM.

\section{Conclusion}

The mere usage of SM does not affect sleep quality. Instead, sleep quality is affected by the duration of SM usage during the day and/or night, as well as the mode and purpose of SM use. Additionally, sleep quality may be affected by complications associated with excessive SM usage, such as mental health issues and lack of physical activity.

\section{Acknowledgments}

We wish to express our sincere thanks to Prof. Sameeh M. Alalmaie, Chairman of Family and Community Medicine Department, College of Medicine, Imam Abdulrahman Bin Faisal University, and all faculty 
members for their help and support. We also thank all students for their participation in this study.

\section{Disclosure}

The authors report no conflicts of interest in this work.

\section{References}

1. Saygın M, Önder Öztürk TG, Has M, et al. Investigation of sleep quality and sleep disorders in students of medicine. Turk Thorac $J$. 2016;17(4):132. doi:10.5578/ttj.30513

2. Levenson JC, Shensa A, Sidani JE, Colditz JB, Primack BA. The association between social media use and sleep disturbance among young adults. Prev Med. 2016;85:36-41. doi:10.1016/j. ypmed.2016.01.001

3. Hoefelmann LP, da Silva Lopes A, da Silva KS, Moritz P, Nahas MV. Sociodemographic factors associated with sleep quality and sleep duration in adolescents from Santa Catarina, Brazil: what changed between 2001 and 2011? Sleep Med. 2013;14(10):1017-1023. doi:10.1016/j.sleep.2013.05.015

4. Mirghani HO, Mohammed OS, Almurtadha YM, Ahmed MS. Good sleep quality is associated with better academic performance among Sudanese medical students. BMC Res Notes. 2015;8(1):706 doi:10.1186/s13104-015-1712-9

5. Alsulami A, Bakhsh D, Baik M, Merdad M, Aboalfaraj N. Assessment of sleep quality and its relationship to social media use among medical students. Med Sci Educ. 2019;29(1):157-161. doi:10.1007/s40670-018-00650-9

6. Park S. Association between short sleep duration and obesity among South Korean adolescents. West J Nurs Res. 2011;33(2):207-223. doi:10.1177/0193945910371317

7. Narang I, Manlhiot C, Davies-Shaw J, et al. Sleep disturbance and cardiovascular risk in adolescents. CMAJ. 2012;184(17):E913-E920. doi:10.1503/cmaj.111589

8. Choueiry N, Salamoun T, Jabbour H, El Osta N, Hajj A, Khabbaz LR. Insomnia and relationship with anxiety in university students: a cross-sectional designed study. PLoS One. 2016;11(2): e0149643. doi:10.1371/journal.pone.0149643

9. Kim SY, Kim M-S, Park B, Kim J-H, Choi HG. Lack of sleep is associated with internet use for leisure. PLoS One. 2018;13(1): e0191713. doi:10.1371/journal.pone.0191713

10. Kim J-H, Park E-C, Yoo K-B, Park S. The association between short or long sleep times and quality of life (QOL): results of the Korea National Health and Nutrition Examination Survey (KNHANES IVV). J Clin Sleep Med. 2015;11(06):625-634. doi:10.5664/jcsm.4772

11. Pasch KE, Latimer LA, Cance JD, Moe SG, Lytle LA. Longitudinal bi-directional relationships between sleep and youth substance use. $J$ Youth Adolesc. 2012;41(9):1184-1196. doi:10.1007/s10964-0129784-5

12. Killgore WD. Effects of sleep deprivation on cognition. Progress in Brain Research. 2010;185:105-129. doi:10.1016/B978-0-444-537027.00007-5

13. Elagra MI, Rayyan MR, Alnemer OA, et al. Sleep quality among dental students and its association with academic performance. J Int Soc Prev Community Dent. 2016;6(4):296. doi:10.4103/22310762.186788

14. Dewald JF, Meijer AM, Oort FJ, Kerkhof GA, Bögels SM. The influence of sleep quality, sleep duration and sleepiness on school performance in children and adolescents: a meta-analytic review. Sleep Med Rev. 2010;14(3):179-189. doi:10.1016/j.smrv.2009.10.004

15. Sampasa-Kanyinga H, Hamilton HA, Chaput JP. Use of social media is associated with short sleep duration in a dose-response manner in students aged 11 to 20 years. Acta Paediatr. 2018;107(4):694-700. doi:10.1111/apa.14210
16. Dewing M. Social Media: An Introduction. Vol. 1. Library of Parliament Ottawa; 2010.

17. Woods HC, Scott H. \# Sleepyteens: social media use in adolescence is associated with poor sleep quality, anxiety, depression and low self-esteem. J Adolesc. 2016;51:41-49. doi:10.1016/j. adolescence.2016.05.008

18. Suleiman KH, Yates BC, Berger AM, Pozehl B, Meza J. Translating the Pittsburgh sleep quality index into Arabic. West J Nurs Res. 2010;32(2):250-268. doi:10.1177/0193945909348230

19. Kroenke K, Spitzer RL, Williams JB. The patient health questionnaire-2: validity of a two-item depression screener. Med Care. 2003;41(11):1284-1292. doi:10.1097/01. MLR.0000093487.78664.3C

20. Plummer F, Manea L, Trepel D, McMillan D. Screening for anxiety disorders with the GAD-7 and GAD-2: a systematic review and diagnostic metaanalysis. Gen Hosp Psychiatry. 2016;39:24-31. doi:10.1016/j.genhosppsych.2015.11.005

21. Shrier I, Platt RW. Reducing bias through directed acyclic graphs. BMC Med Res Methodol. 2008;8(1):70. doi:10.1186/1471-2288-8-70

22. Farzaneh F, Momayyezi M, Lotfi MH. Relationship between quality of sleep and mental health in female students of Shahid Sadoughi University of Medical Sciences (2015). J Fundam Ment Health. 2018;20(2):167-171.

23. Silva M, Chaves C, Duarte J, Amaral O, Ferreira M. Sleep quality determinants among nursing students. Procedia Soc Behav Sci. 2016;217:999-1007. doi:10.1016/j.sbspro.2016.02.090

24. Lee S-Y, Wuertz C, Rogers R, Chen Y-P. Stress and sleep disturbances in female college students. Am J Health Behav. 2013;37 (6):851-858. doi:10.5993/AJHB.37.6.14

25. Cates ME, Clark A, Woolley TW, Saunders A. Sleep quality among pharmacy students. Am J Pharm Educ. 2015;79(1):9. doi:10.5688/ ajpe79109

26. Merdad RA, Merdad LA, Nassif RA, El-Derwi D, Wali SO. Sleep habits in adolescents of Saudi Arabia; distinct patterns and extreme sleep schedules. Sleep Med. 2014;15(11):1370-1378. doi:10.1016/j. sleep.2014.06.008

27. Lazaratou H, Dikeos DG, Anagnostopoulos DC, Sbokou O, Soldatos CR. Sleep problems in adolescence: a study of senior high school students in Greece. Eur Child Adolesc Psychiatry. 2005;14 (4):237-243. doi:10.1007/s00787-005-0460-0

28. Kar SS, Agrawala M. A study on sleep quality during different phases of menstrual cycle among medical students. J Evid Based Med Healthc. 2018;5(33):2419-2423. doi:10.18410/jebmh/2018/499

29. Lin P-C, Chen C-H, Pan S-M, et al. Atypical work schedules are associated with poor sleep quality and mental health in Taiwan female nurses. Int Arch. Occup Environ Health. 2012;85 (8):877-884. doi:10.1007/s00420-011-0730-8

30. Kaneita Y, Ohida T, Uchiyama M, et al. The relationship between depression and sleep disturbances: a Japanese nationwide general population survey. $J$ Clin Psychiatry. 2006;67(02):196-203. doi:10.4088/JCP.v67n0204

31. Ramsawh HJ, Stein MB, Belik S-L, Jacobi F, Sareen J. Relationship of anxiety disorders, sleep quality, and functional impairment in a community sample. J Psychiatr Res. 2009;43(10):926-933. doi:10.1016/j.jpsychires.2009.01.009

32. Watson E, Coates A, Kohler M, Banks S. Caffeine consumption and sleep quality in Australian adults. Nutrients. 2016;8(8):479. doi: $10.3390 /$ nu 8080479

33. McLellan TM, Caldwell JA, Lieberman HR. A review of caffeine's effects on cognitive, physical and occupational performance. Neurosci Biobehav Rev. 2016;71:294-312. doi:10.1016/j. neubiorev.2016.09.001

34. Cole JS. A survey of college-bound high school graduates regarding circadian preference, caffeine use, and academic performance. Sleep Breath. 2015;19(1):123-127. doi:10.1007/s11325-014-0976-y 
35. Andreassen CS, Pallesen S, Griffiths MD. The relationship between addictive use of social media, narcissism, and self-esteem: findings from a large national survey. Addict Behav. 2017;64:287-293. doi:10.1016/j.addbeh.2016.03.006

36. Hawi NS, Samaha M. The relations among social media addiction, self-esteem, and life satisfaction in university students. Soc Sci Comput Rev. 2017;35(5):576-586. doi:10.1177/0894439316660340
37. Xie X, Dong Y, Wang J. Sleep quality as a mediator of problematic smartphone use and clinical health symptoms. J Behav Addict. 2018;7(2):466-472. doi:10.1556/2006.7.2018.40

38. Kim Y-J, Jang H, Lee Y, Lee D, Kim D-J. Effects of internet and smartphone addictions on depression and anxiety based on propensity score matching analysis. Int J Environ Res Public Health. 2018;15 (5):859. doi:10.3390/ijerph15050859

\section{Publish your work in this journal}

Nature and Science of Sleep is an international, peer-reviewed, open access journal covering all aspects of sleep science and sleep medicine, including the neurophysiology and functions of sleep, the genetics of sleep, sleep and society, biological rhythms, dreaming, sleep disorders and therapy, and strategies to optimize healthy sleep.
The manuscript management system is completely online and includes a very quick and fair peer-review system, which is all easy to use. Visit http://www.dovepress.com/testimonials.php to read real quotes from published authors. 